\title{
The Effect of Applying Accreditation Standards on Patients' Satisfaction in Jordanian Governmental Hospitals
}

\author{
Naser Ibrahim Saif ${ }^{1}$ \\ ${ }^{1}$ Faculty of Administrative and Financial Science, Philadelphia University, Jordan \\ Correspondence: Naser Ibrahim Saif, Faculty of Administrative and Financial Science, Philadelphia University, \\ P.O. Box 849, Amman 11941, Jordan. E-mail: naser.saif@ymail.com
}

Received: June 22, 2018

doi:10.5539/mas.v12n9p57

\author{
Accepted: July 6, $2018 \quad$ Online Published: August 14, 2018 \\ URL: https://doi.org/10.5539/mas.v12n9p57
}

\begin{abstract}
Most hospitals follow voluntary or mandatory accreditation standards, which are widely believed to improve patient satisfaction. The current descriptive, qualitative study explored physicians' and nurses' opinions and beliefs regarding implemented accreditation standards on patient satisfaction at accredited Jordanian public hospitals in 2017. Data were collected using a structured questionnaire with 110 physicians and nurses from three hospitals (response rate $=71 \%$ ). SPSS version 17 was used to calculate mean values, standard deviations, regression, and to conduct t-tests (significant p-values $<.05$ ). Results indicated medium levels of patient satisfaction in accredited hospitals, suggesting that patient satisfaction levels require improvement. Future research should identify causal relationships between implementing accreditation standards and patient satisfaction.
\end{abstract}

Keywords: patient satisfaction, hospital accreditation, government accredited hospitals

\section{Introduction}

In recent decades, business organizations have been subjected to various scientific and economic phenomena. The most prominent of these are openness and globalization, the orientation towards market economies, regional and global blocs, the information revolution, and technological development (Saif, 2016a). Business organizations, in general, and health institutions, specifically, have therefore sought to achieve a sustainable competitive advantage through their available capabilities and resources. Healthcare have become convinced of the importance and necessity of change and attention to Total Quality Management (TQM), and the continuous adoption and improvement of the efficiency and effectiveness of its performance to ensure its survival (Ross, 2017).

TQM and accreditation, as a management philosophy, are a method to help organizations to acquire competitive advantages that enable them to develop considering successive environmental changes (Westcott, 2013). Further, considering the successes achieved by the industrial sector because of the application of TQM and accreditationregarding both product quality and efficiency - service sector organizations, including healthcare organizations, could gain experience by following the same path (Saif, 2016b). Consequently, hospitals implemented accreditation standards to improve their use of available resources, improve their services, and improve patient satisfaction (Oliveira \& Matsuda, 2016).

In view of the challenges faced by all sectors of the Jordanian health system and the lack of international accreditation awards by Jordanian hospitals, to achieve this, hospitals are concerned with the implementation of accreditation standards as stated by the Health Care Accreditation Council (HCAC) in Jordan (2018). Due to the importance of the hospital within the health care system for division to patients and their his satisfaction, the specific goals for specified assignments required to be undertaken in this study are as follows:

\subsection{Study Purpose and Questions}

The purpose of this study was to understand the application levels of accreditation standards in accredited government hospitals and the impact of these standards on patients' satisfaction from the perspectives of doctors and nurses during the years 2010-2017. Specifically, this study sought to answer the following study questions:

Q1: What are the application levels of accreditation standards in accredited Jordanian government hospitals?

Q2: What are the levels of patient satisfaction in accredited Jordanian public hospitals?

Q3: What is the effect of the application of accreditation standards on patient satisfaction in accredited 
Jordanian public hospitals?

\subsection{Hypothesis}

I hypothesized that the application of accredited standards will not improve patients' satisfaction in accredited Jordanian public hospitals.

\subsection{Procedural Definitions (HCAC, 2018)}

\subsubsection{TQM Standards}

They are expressed by applying the accreditation standards as stated by the HCAC, which include quality standards for leadership, patient care, safety systems, information, hotel services, human resources, diagnostic services, legal responsibility, and continuous improvement.

\subsubsection{Leadership Standards}

These reflect the keenness of the hospital director to establish a system to supervise the available resources in hospitals, implement the comprehensive quality program, ensure the hospital's application of all Jordanian laws and regulations, and implement a clear plan for communication between the administration and all employees.

\subsubsection{Patient Care Standards}

These ensure that the hospital administration follows a series of procedures to provide health services to patients from the time they enter the hospital until they are discharged. The treatment plan includes the participation of all the required specialties in the provision of healthcare services and providing medical care according to the HCAC's guidelines.

\subsubsection{Safety Systems Standards}

These are based on the application of two basic components: medical safety and environmental safety in the hospital. These require the implementation of an infection control plan, a staff health program, a physical environment management plan, and inspection and maintenance of the physical facilities of the hospital.

\subsubsection{Information Management Standards}

Medical records are provided to all patients as a tool for communication and coordination between all health service providers, and to provide the necessary information for scientific research and continuing medical education.

\subsubsection{Accommodations Service Standards}

These include three basic components: housekeeping, cleaning services, and laundry services. This helps organize the necessary procedures for the provision of food services, dietary plans, and assistance with therapeutic plan.

\subsubsection{Human Resource Standards}

These ensure a sufficient amount of qualified, diverse staff are available in the hospital through the application of a unified recruitment plan, training and improvement, job descriptions for all employees, and a unified performance appraisal policy.

\subsubsection{Diagnostic Service Standards}

These include the consistent provision of laboratory services and radiography services that are commensurate with the quality and quantity of health services provided by the hospital.

\subsubsection{Social Responsibility Standards}

These ensure that the hospital responds to the rights, community needs, customs, traditions, and beliefs of patients. Informed consent must be obtained from patients of their representatives prior to health services, and the hospital administration must take responsibility for patients' rights.

\subsubsection{Continuous Improvement Standards}

These include the adoption of a comprehensive quality methodology and continuous improvement in the hospital. There is also implementation of a system for the reporting of medical accidents and errors as a tool for identifying opportunities for improvement.

\subsubsection{Patient satisfaction}

This includes patient' desire to return to the same hospital for treatment, advising others to review the hospital, and general satisfaction with the services provided by the hospital. 


\subsection{Study Objectives}

By determining the application level of accreditation standards and the impact on patients' satisfaction, this study will be able to provide appropriate recommendations that may improve the overall quality of care in Jordanian hospitals.

\subsection{Study Boundaries}

This study addressed the accreditation standards in Jordanian government hospitals (specifically, the geographical regions of the Hashemite Kingdom) that were approved between 2010 and 2017.

\subsection{Theoretical Framework}

\subsubsection{Jordanian Government Hospitals}

The Jordanian Ministry of Health provides its health services through 31 public hospitals, distributed throughout the Kingdom's governorates, with a high percentage of coverage for health services provided to citizens (Strategic Plan, 2016). These hospitals comprise 4,235 beds and constitute $38.3 \%$ of the total number of hospital beds in Jordan (Information Directorate, 2016).

\subsubsection{Hospital Accreditation}

The process of hospital accreditation is a long and painstaking process that often requires significant changes in the customary practices and behavior of individuals. Employees are encouraged to use their creative potential and avoiding performing traditional work that will lead to stagnation. This process requires the hospital staff members to conduct a comprehensive assessment of their current performance and to identify the practices that must be changed to reach creative solutions to problems in the pursuit of success and competition. This includes a set of standards supporting the improvement of patient health; satisfying hospital auditors; and continuous improvement of ideas, performance, and goals (Jordan Ministry of Health, 2007). In summary, hospital accreditation is an integrated process that includes a set of steps by which the hospital is evaluated to see if it meets a set of standards and foundations designed to improve the quality of healthcare services. This assessment is usually conducted by a neutral, independent, non-hospital body.

The standard is a level that defines the quality of the work to be reached or achieve accreditation. It covers all aspects of hospital work such as the care of patients and their families, access to health care and continuity, diagnostic services, dominant leadership style, safety and support services, and quality improvement. Application of accreditation standards will improve information management, human resources education and training, and nursing services.

Several of the 31 major government hospitals in Jordan are seeking to develop their health services to keep abreast of international developments and to obtain accreditation. Hospital staff are educated about achievement of accreditation standards, and self-assessments regarding compliance with established standards are conducted to gain a certificate of accreditation.

\subsubsection{Patient Satisfaction}

The clearest way to judge the appropriateness of a service is to check whether the beneficiaries of the service are satisfied. Satisfaction is generally defined as a basic criterion for judging quality, and hospitals are not excluded from this principle (Barofsky, 2012). In other words, the demand for service adjusts itself according to the achievement of its objectives and the beneficiaries' satisfaction. The usual way of thinking about serving patients is to assume that if the service is dysfunctional, the patients will not be satisfied and that there will be a longitudinal link between the patients' satisfaction and their desire to get the service (Ministry of Health, 2018).

\subsection{Previous Studies}

\subsubsection{Abdelkader (2015)}

This study aimed to measure the quality of health services in government hospitals in Sudan based on the perspective of patients. It examined the major educational hospitals in the state of Khartoum. A soft sample of patients was selected, and a questionnaire was used, which included 22 words to measure the quality of health services. The study found that patients were fully aware of the quality of health services available in government hospitals. In addition, there were no significant differences in the quality of health services in government hospitals regarding gender, age, education, income, and place of residence. The study recommended that hospitals be equipped with the necessary equipment, provide qualified medical personnel, and provide appropriate physical assessments to instill confidence and promote patient safety. 


\subsubsection{Yahyaoui (2014)}

The aim of this study was to identify the level of quality of health services provided by the hospitals in Batna and the satisfaction of patients by revealing the dimensions and standards used to evaluate them. The results of the study showed a positive relationship between the application of health quality standards and patient satisfaction.

\subsubsection{Saif (2013)}

This study was based on the importance of health services provided at primary health centers in Jordan, with a focus on the detection of the trends in service utilization of patients with diabetes. This study was conducted in the central laboratories of the Jordanian Ministry of Health. A quantitative and qualitative approach was used with 340 patients. Data were collected by means of questionnaires, interviews, document review, and annual reports from the Jordanian Ministry of Health. The researchers used descriptive and explanatory statistical measures to analyze questionnaire data. The results indicated that primary healthcare centers provided acceptable services, patients' satisfaction was acceptable, and that the services provided to patients with type 2 diabetes led to acceptable health outcomes.

\subsubsection{Nusseirat (2007)}

This exploratory study examined the views of administrators in private sector hospitals in Amman. This study aimed to determine whether there were significant differences in the degree of hospital application of TQM by analyzing the relationship between the quality and organizational performance of these hospitals. The study population included nine private hospitals with ISO certification, all located in Amman city. The analysis and inspection unit consisted of senior and middle management staff. This study found significant differences regarding performance indicators and patient satisfaction between hospitals. There was also a significant positive relationship between quality and overall performance indicators. This study presented several recommendations; most importantly, was the need to focus on overall quality, and the need for a national model to assess overall quality in the Jordanian health sector.

\subsubsection{Al-Saidi (2007)}

This study identified TQM in Jordanian pharmaceutical production factories and examined patients' satisfaction with Jordanian medicine. The comprehensive quality elements included research and development, the efficiency of employees, the cost of total quality, the control of overall quality, and obtaining certificates of accreditation and quality. Data was connected on satisfaction with regards to medication effectiveness, price, clear usage instructions, packaging, and availability of the drug. The sample consisted of doctors, pharmacists, and drug consumers in Amman Municipality. Al-Saidi noted that TQM in Jordanian pharmaceutical companies was $83.2 \%$, and a positive relationship between organizational factors and customer satisfaction. Consumers' total satisfaction was $62.8 \%$, doctors' degree of satisfaction about drug quality was $49.8 \%$, and pharmacists' satisfaction with the quality of Jordanian medicine was $48 \%$. Al-Saidi recommended the need for Jordanian pharmaceutical companies to integrate, including an increase in their ability to improve their competitive advantage and customer satisfaction, the adoption of a benchmarking strategy for product quality improvement, the revision of the design and drafting of drug-related instruction sheets, implementing a drug pricing policy, and the promotion of scientific research work in Jordanian companies to improve consumer satisfaction.

\subsubsection{Judges (2006)}

This study examined the impact of the adoption of TQM to improve the competitive position of pharmaceutical companies in the Hashemite Kingdom of Jordan. The sample included 17 large pharmaceutical manufacturers and the findings showed that there was a positive correlation between application of TQM and customer satisfaction, suppliers integration, continuous improvement, empowerment of workers, dissemination of quality culture, achievement of competitive position, and expansion of market share.

\subsection{Characteristics of this Study and Previous Studies}

After examining the prior research on TQM and accreditation, the following conclusions can be drawn:

1. The results of most Jordanian and foreign studies have noted the importance of implementing TQM and accreditation in the health sector.

2. Studies addressing TQM and accreditation in health organizations have stressed the importance of continuing to apply this management method because of its benefits to patients' satisfaction.

3. An emphasis on TQM and accreditation is necessary in many countries for the evaluation and accreditation of hospitals. 


\section{Method and Procedure}

Currently, seven government hospitals in Jordan are accredited (Accreditation Board of Health Institutions, 2018). This study examined three of these hospitals (42\%): Prince Hamza Hospital in Amman, Zarqa Hospital in Zarqa Governorate, and Jerash Hospital Government in Jerash Governorate. The study population included all doctors and nurses in the three accredited hospitals $(\mathrm{n}=925)$. Participants comprised a random sample of doctors and nurses from the participating hospitals, with a final sample size of 130 , or $14 \%$ of the total population, who were selected from the community hospital study records. The researcher and his assistants distributed 130 questionnaires after obtaining approval from the hospitals' scientific research committees. Overall, 110 valid questionnaires were returned (response rate $=84 \%$ ).

\subsection{Collect Study Data}

Data were collected by secondary sources of information including traditional and electronic magazines and periodicals and the outcome of several seminars and specialized scientific articles in the Jordanian health system. In addition, the Internet was used, especially sites that specialized in quality management and the Jordanian accreditation program. The primary source of data collection was the questionnaire, which was adopted in many similar studies (Gorji, 2011; Haj-Ali, Karroum, Natafgi, \& Kassak, 2014; Tabrizi, Gharibi, \& Wilson, 2011). The questionnaire consisted of 44 questions. Responses to all 44 questions were measured on a five-point Likert scale: 1 , strongly agree; 2 , agree; 3 , not sure (do not know); 4, disagree; and 5 , strongly disagree. Respondents were, consequently, asked to indicate their level of agreement with each statement on the questionnaire

To ascertain questionnaire validity, the researcher presented the questionnaire to three distinguished professors and amendments were made according to their recommendations. The devised questionnaire was highly reliable (Cronbach's $\alpha=.846$ ). The questionnaire consisted of three parts:

Part 1: Metadata on employee characteristics

Part 2: Application data of the accreditation standards

Part 3: Patients' satisfaction data.

The introduction of the questionnaire explained the ethical aspects of scientific research in terms of freedom of participation and withdrawal and that the data would be used only for the current study and confidentiality of the data would be maintained.

\subsection{Statistical Analyses}

To answer the study questions and to verify the level of application of accreditation standards and patients' satisfaction, all data were entered into the computer and processed using SPSS version 17 (SPSS Inc., Chicago, IL, USA), which included data classification, descriptive statistics (means and standard deviations), and t-tests to determine the trends of sample members towards the application of independent variables. A linear regression analysis was conducted to test the study hypothesis with a significance level of $\mathrm{p}<.0 .05$.

\section{Results and Discussion}

\subsection{Participants' Characteristics}

The study sample consisted of doctors and nurses working in accredited hospitals. Overall, $37 \%$ of the respondents were doctors, most were older than age 27 (45.5\%), and 60.3\% were female. Further, $75.3 \%$ of respondents had greater than 5 years of experience.

To answer the first study question - What are the application levels of accreditation standards in Jordanian government hospitals? - the mean value and standard deviation of each component were calculated (Table 1). Values 1-2.33, 2.34-3.67, and 3.68-5 were considered weak, moderate, and high, respectively. Results indicate that most means levels are moderate; however, two are low (driving and hotel services). The results can be interpreted as the complacency of the evaluators in assessing accreditation standards, since the hospital accreditation experience is new in Jordan, or doctors and nurses believe there should be higher standards for applying these standards. Failure to improve this standards implementation could lead hospitals to lose their accreditation certificate in subsequent years.

Table 1 shows that the moderate amount of desire among doctors and nurses to care for patients may be due to the lack of incentives and returns they receive for their efforts. Further, the moderate application of safety standards was due to the weak commitment to safety application, which is common in most Jordanian institutions (Saleh, 2015). The moderate level of information management standards indicates a lack of interest and high appreciation of the importance of information management in hospitals. We often hear about the loss or damage of patients' 
medical files (Hakeem, 2017). On the other hand, it is hoped that a wise application program for computerization of medical files will improve this standard. Regarding the weak result for hotel service standards, this can be attributed to the large volume of health services provided in hospitals and the allocation of most of the budgets going to medical treatment and equipment. The interest in human resources management, development, and continuous training was also low, which is consistent across all hospitals in Jordan (Saif, 2013).

Table 1 also shows a moderate level of attention to diagnostic tools. Hospitals are often interested in providing diagnostic tools; however, limited resources prevent access to such resources, but remain within the limits of treatment for patients. In addition, the sample seemed to desire improving health services provision and commitment to apply the rules of continuous improvement.

Table 1. The Mean Value and the Standard Deviation of the Responses of Sample Members from the Application Levels of Accreditation Standards in Hospitals

\begin{tabular}{llll}
\hline No. & Accreditation standards & Mean & Standard deviation \\
\hline 1 & Leadership standards & 1.67 & 0.47 \\
2 & Patient care standards & 3.05 & 1.1 \\
3 & Safety standards & 2.99 & 1.1 \\
4 & Information management standards & 2.63 & 0.90 \\
5 & Hotel service standards & 1.38 & 0.48 \\
6 & Human resource management standards & 2.89 & 1.1 \\
7 & Diagnostic service standards & 3.51 & 0.98 \\
8 & Social responsibility standards & 3.40 & 0.97 \\
9 & Continuous improvement standards & 3.11 & 1.1 \\
\hline Total & & 2.62 & 0.62 \\
\hline
\end{tabular}

Regarding the second research question-What are the levels of patients' satisfaction in accredited Jordanian government hospitals? - the results confirmed a moderate level of satisfaction, indicating room for improvement (Table 2).

Lastly, regarding the third research question - what is the effect of the application of accreditation standards on patient satisfaction in accredited Jordanian public hospitals? - The following null hypotheses were formulated:

$\mathrm{H}_{0} 1$ : Jordanian accredited hospitals do not apply accreditation standards.

$\mathrm{H}_{0} 2$ : The level of patient satisfaction in accredited Jordanian hospitals is low.

$\mathrm{H}_{0} 3$ : There is no effect on the application of patient satisfaction standards in accredited Jordanian public hospitals.

To test both the first and second null hypotheses, a one-sample t-test was conducted (Table 2). The outputs show that the weighted $t$-value was higher than the tabular value and the significance level was $<.001$; therefore, the null hypothesis was rejected, and the alternative hypothesis was accepted-that accredited hospitals apply accreditation standards and that patient satisfaction is not low.

Table 2. T-test Results

\begin{tabular}{ccccc}
\hline Hypothesis & Mean & SD & $\mathrm{t}$ & Sig. \\
\hline $\mathrm{H}_{0} 1$ & 2.62 & .62 & 44.1 & $<.001$ \\
$\mathrm{H}_{0} 2$ & 3.1 & 1.2 & 26.2 & $<.001$ \\
\hline
\end{tabular}

To test the third null hypothesis, since both variables are quantified, we conducted a linear regression analysis (Table 3). Consequently, the results demonstrated that we were able to rejected the null hypothesis and accepted the alternative hypothesis - that there is an effect on the application of patient satisfaction standards in accredited Jordanian government hospitals.

Table 3. Linear Regression Analysis Test Results

\begin{tabular}{cccccc}
\hline \multirow{2}{*}{$\mathrm{H}_{0} 3$} & $\mathrm{R}$ & $\mathrm{R}^{2}$ & $\mathrm{~F}$ & $\mathrm{~B}$ & Sig. \\
\cline { 2 - 6 } & .60 & .36 & 59.8 & .59 & $<.001$ \\
\hline
\end{tabular}




\subsection{Recommendations}

Considering the findings of the study, the researcher recommends the following:

1. There is a need for leadership to apply accreditation standards to improve patient satisfaction, as well as the need to select leaders of government hospitals capable of bringing about change, and the apply modern management methods.

2. Jordanian hospitals need to increase their attention to the application of patient care, information, safety, information management, human resources, diagnostic services, social responsibility, and continuous improvement. The application of these standards has only led to satisfactory patient satisfaction; therefore, hospitals need to do more to improve levels and to achieve higher levels of patient satisfaction.

3. Hospitals continue to need to provide additional resources and take care of hotel services, as they have a key role in improving patient satisfaction.

4. As this study did not evaluate patient satisfaction from their point of view, future research is needed to examine the impact of accreditation standards on patient satisfaction.

\section{References}

Ayman the meanings. (2009). Attitudes of Directors at the Jordanian Ministry of Labor to the Role of Knowledge Management in Job Performance. The Jordanian Journal of Business Administration, 5(3), 371-402.

Barofsky, I. (2012). Quality: Its Definition and Measurement as Applied to the Medically Ill. East Standwich, MA: Springer.

Brown, J. A. (2005). The Healthcare Quality Handbook. Pasadena, USA: JB Quality Solutions.

Council for Accreditation of Hospitals. (2009). Directory of Jordanian Hospitals Accreditation. Jordan.

Gorji, M. (2011). The study of the relationship between total quality management and service quality improvement leading to an optimal model presentation. Australian Journal of Basic and Applied Sciences, 5(11), 17421749 .

Haj-Ali, W., Karroum, L., Natafgi, N., \& Kassak, K. (2014). Exploring the relationship between accreditation and patient. International Journal of Health Policy Management, 3(6), 341-346.

Health Care Accreditation Council. (2018). About the health care accreditation council. Retrieved March 4, 2018, from http://hcac.jo/en-us/

Judges, M. (2006). Following the Adoption of the Comprehensive Quality Strategy in Improving the Competitive Position: Jordanian Pharmaceutical Companies. Amman.

Oliveira, J., \& Matsuda, L. (2016). Benefits and difficulties in the implementation of hospital accreditation: The voice of quality managers. Escola Anna Nery, 20(1), 63-69.

Regional Committee for the Eastern Mediterranean. (2008). Accreditation of Hospitals and Medical Education Institutions-Challenges and Future Directions of Hospitals. World Health Organization, Cairo Regional Office.

Ross, J. (2017). Total Quality Management: Text, Cases, and Readings. USA: US Government Works.

Saidi, A. (2007). The Impact of the Application of TQM on the Satisfaction of Customers in the Jordanian Pharmaceutical Production Plants. Amman Arab University for Graduate Studies.

Saif, N. (2016a). Quality of Health Services and Patients' Satisfaction in Accredited and Non-Accredited Hospitals. International Journal of Business and Management, 11(10), 298-305.

Saif, N. (2016b). Workplace stress in comprehensive health Centers and its impact on career commitment. International Business Research, 9(7), 71-79.

Saif, N., \& Sartawi, K. (2013). Relationship between human resource management practices and perceived performance of employees in Jordanian hospitals. European Journal of Business and Management, 5(22), 129-136.

Saleh, S., Saif, N., \& Sartawi, K. (2015). CPTED and workplace violence in Jordanian public hospitals. Asian Social Science, 11(4), 336-347.

Scientific Research Committee. (2017). Ministry of Health. Amman Jordan.

Strategic Plan. (2016). Strategic Plan of the Ministry of Health 2012-2016. Ministry of Health of Jordan. 
Tabrizi, J., Gharibi, F., \& Wilson, A. (2011). Advantages and disadvantages of health care accreditation models. Health Promotion Perspectives, 1(1), 1-31.

Westcott, R. (2013). The Certified Manager of Quality/Organizational Excellence Handbook. (F. Edition, Ed.) Wisconsin.

Yahyaoui, E. (2014). Evaluation of the quality of Health Services and the Level of Satisfaction of our Customers: A Field Study in the Medical Institutions of Batna. Journal of the Researcher, 14, 34-41.

\section{Copyrights}

Copyright for this article is retained by the author(s), with first publication rights granted to the journal.

This is an open-access article distributed under the terms and conditions of the Creative Commons Attribution license (http://creativecommons.org/licenses/by/4.0/). 